\title{
POSITRON ANNIHILATION STUDY OF THE AGEING EFFECTS IN THE Cu-Zn-Sn PARENT PHASE*
}

\author{
J.E. Frackowiak, K. Plotkowski and A. Salamon \\ Institute of Physics and Chemistry of Metals, Silesian University \\ Bankowa 12, 40-007 Katowice, Poland \\ (Received February 10, 1995; in final form May 9, 1995)
}

\begin{abstract}
A study of ageing effects on the structure of $\mathrm{Cu}-\mathrm{Zn}-\mathrm{Sn}$ shape memory alloys was performed using the ${ }^{119} \mathrm{Sn}$ Mössbauer spectroscopy and positron annihilation techniques (the positron lifetime and Doppler broadening lineshape $S$-parameter measurements). Two stages of ageing at $200^{\circ} \mathrm{C}$ connected with redistribution of $\mathrm{Sn}$ atoms were observed.
\end{abstract}

PACS numbers: 61.66.Dk, 61.72.-y, 78.70.Bj, 76.80.+y

\section{Introduction}

Copper based alloys are being examined intensively due to their model character and their wide application to technology. Particular attention has been paid recently to a ternary $\mathrm{Cu}-\mathrm{Zn}-\mathrm{Sn}$ compound because of the appearance of the reversible martensite transformation and connected shape memory effect [1].

Tin interferes with the recovery of the quenched $\mathrm{Cu}-\mathrm{Zn}$ alloys $[2,3]$. Therefore, there has been an interest in the migration of $\mathrm{Sn}$ atoms, $\mathrm{Sn}$-vacancy pair and the thermal stability of clusters of vacancies-Sn atoms in $\mathrm{Cu}-\mathrm{Zn}-\mathrm{Sn}$ alloys.

The Mössbauer technique is useful for studying the local state of the Mössbauer nuclei and their surroundings. The Mössbauer ${ }^{119} \mathrm{Sn}$ analysis provides information about $\mathrm{Sn}$ to clarify the annealing process.

The positron annihilation technique is sensitive to the state of vacancies and it can clarify the precipitation mechanism through the change in state of these defects. The Mössbauer and the positron annihilation techniques are complementary to each other.

\section{Experimental procedures}

The $\mathrm{Cu}-20$ wt\% $\mathrm{Zn}-15 \mathrm{wt} \% \mathrm{Sn}(\mathrm{A})$ and $\mathrm{Cu}-12.5 \mathrm{wt} \% \mathrm{Zn}-20 \mathrm{wt} \%$ Sn (B) alloys were prepared from $4 \mathrm{~N}$ purity elements in the arc furnace. In order to obtain the $\beta_{1}$ parent phase, the samples were betatized at $740^{\circ} \mathrm{C}$ and quenched into water at room temperature.

*This paper was presented at the 26th Polish Seminar on Positron Annihilation, Pokrzywna (Poland) 1994. 
A standard Mössbauer spectrometer operating in the constant acceleration mode was used. The source was ${ }^{119} \mathrm{Sn}$ nuclei in $\mathrm{BaSnO}_{3}$ with activity about $5 \mathrm{mCi}$. For Mössbauer investigations, samples were chemically thinned to $45 \mu \mathrm{m}$ thick foil. The ageing process was carried out at $200^{\circ} \mathrm{C}$ for the range $0 \div 20 \mathrm{~min}$.

Positron annihilation Doppler broadening and positron lifetime measurements were performed. The Doppler broadening of the $511 \mathrm{keV}$ annihilation line was measured with an HPGe detector. The $511 \mathrm{keV}$ annihilation line was characterized by an $S$-parameter (defined as the fraction of full energy counts falling within a central integration window). The value of this parameter is a measure for the trapping of the positrons at defects.

Measurements of positron lifetimes in $\mathrm{Cu}-\mathrm{Zn}-\mathrm{Sn}$ alloys were performed using a spectrometer operating in a "fast-slow" system. The full width at half maximum of the resolution curve was $310 \mathrm{ps}$. The external positron source ${ }^{22} \mathrm{NaCl}$ with $30 \mu \mathrm{Ci}$ activity was covered with kapton foils of a thickness of $1 \mathrm{mg} / \mathrm{cm}^{2}$. The intensity of the positron annihilation in the source confining material $\left(\tau_{\text {kapton }}=384 \pm 5 \mathrm{ps}\right.$ ) was about $14 \%$ [4].

\section{Results and discussion}

\subsection{Mössbauer measurements}

It was shown [5] that the Mössbauer spectroscopy can be used in a phase analysis of the tin brass. The phases $\alpha, \beta$ and $\gamma$ are represented in the Mösbauer spectrum by single lines with different isomer shift and linewidths. The value of the isomer shift decreases with increasing $\mathrm{Zn}$ content from about $-0.36 \mathrm{~mm} / \mathrm{s}$ for $\gamma$ phase to about $-1.1 \mathrm{~mm} / \mathrm{s}$ for $\alpha$ phase. The value of the isomer shift is also sensitive to the process of ordering in the $\beta$ phase.

The Mössbauer spectra of investigated samples are presented in Fig. 1. Through a careful computer analysis the spectra were fitted by single Lorentzian line in the first step and by double Lorentzian lines in the second step. The results

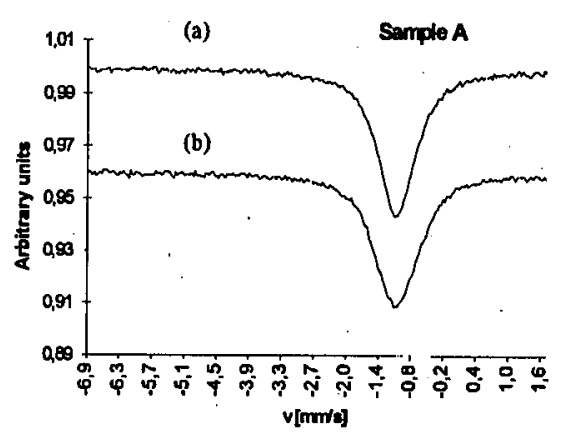

Fig. 1. Mössbauer spectra of as-quenched (a) and aged for $20 \mathrm{~min}$ at $200^{\circ} \mathrm{C}$ (b) sample A. 
TABLE I

Results of the deconvolution of the Mössbauer spectra for sample A into single $(I S, \Gamma)$ and double $\left(I S_{1}, \Gamma_{1}\right)\left(I S_{2}, \Gamma_{2}\right)$ components.

\begin{tabular}{c|c|c|c|c|c|c}
\hline \hline $\begin{array}{c}\text { Ageing } \\
\text { time }[\mathrm{min}]\end{array}$ & $\begin{array}{c}I S \\
{[\mathrm{~mm} / \mathrm{s}]}\end{array}$ & $\begin{array}{c}\Gamma \\
{[\mathrm{mm} / \mathrm{s}]}\end{array}$ & $\begin{array}{c}I S_{1} \\
{[\mathrm{~mm} / \mathrm{s}]}\end{array}$ & $\begin{array}{c}\Gamma_{1} \\
{[\mathrm{~mm} / \mathrm{s}]}\end{array}$ & $\begin{array}{c}I S_{2} \\
{[\mathrm{~mm} / \mathrm{s}]}\end{array}$ & $\begin{array}{c}\Gamma_{2} \\
{[\mathrm{~mm} / \mathrm{s}]}\end{array}$ \\
\hline 0 & -1.1 & 0.82 & - & - & - & - \\
2 & -1.1 & 0.82 & - & - & - & - \\
5 & -1.1 & 0.83 & - & - & - & - \\
8 & -1.08 & 0.87 & - & - & - & - \\
11 & -1.08 & 0.9 & -1.16 & 0.84 & -0.87 & 0.72 \\
14 & -1.09 & 0.91 & -1.15 & 0.83 & -0.78 & 0.71 \\
17 & -1.09 & 0.92 & -1.16 & 0.81 & -0.77 & 0.7 \\
20 & -1.08 & 0.95 & -1.2 & 0.82 & -0.84 & 0.74
\end{tabular}

TABLE II

Results of the deconvolution of the Mössbauer spectra for sample B into a single component.

\begin{tabular}{c|c|c}
\hline \hline $\begin{array}{c}\text { Ageing } \\
\text { time }[\mathrm{min}]\end{array}$ & $\begin{array}{c}I S \\
{[\mathrm{~mm} / \mathrm{s}]}\end{array}$ & $\begin{array}{c}\Gamma \\
{[\mathrm{mm} / \mathrm{s}]}\end{array}$ \\
\hline 0 & -1.1 & 0.8 \\
2 & -1.08 & 0.78 \\
5 & -1.1 & 0.75 \\
8 & -1.08 & 0.8 \\
11 & -1.09 & 0.79 \\
14 & -1.08 & 0.8 \\
17. & -1.08 & 0.83
\end{tabular}

of this analysis are given in Table I and Table II. The value of isomer shift (IS) and linewidth $(\Gamma)$ for quenched samples are typical for $\beta_{1}$ parent phase [5]. However the annealing process at $200^{\circ} \mathrm{C}$ causes broadening of the Mössbauer line.

The variation in $\Gamma$ versus annealing time at $200^{\circ} \mathrm{C}$ is showed in Fig. 2. A two stages of ageing are observed. For sample $A$, the value of linewidth of a spectrum remain constant up to $5 \mathrm{~min}$ and then slowly increases. It is interesting that the Mössbauer spectra of samples annealed at $200^{\circ} \mathrm{C}$ for $10 \div 20$ min can be decomposed into two components. The first and second component can be attributed to $\mathrm{Sn}$ atoms substituted in the two different sublattices of $\mathrm{DO}_{3}$ structure [3]. However, the parameters of the second component are very similar to the parameters of the $\alpha$ phase. This suggests that a precipitation process starts after 10 min of annealing at $200^{\circ} \mathrm{C}$. 

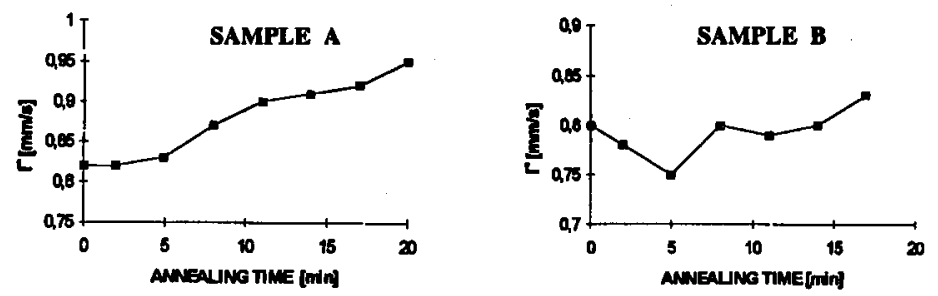

Fig. 2. Linewidth $\Gamma$ of the Mössbauer spectra of samples A and B.

For sample B, the linewidth decreases for up to $5 \mathrm{~min}$ of ageing at $200^{\circ} \mathrm{C}$ and then slowly increases. Only a single component was found as a result of a computer analysis. The variation in $\Gamma$ and the value of isomer shift $(I S \approx-1.1 \mathrm{~mm} / \mathrm{s})$ suggest that in this sample an ordering process takes place out up to 5 min of ageing at $200^{\circ} \mathrm{C}$. In the second stage, increased number of $\mathrm{Sn}$ atoms in the neighbourhood of ${ }^{119} \mathrm{Sn}$ nuclei connected with the pre-precipitation process of the $\alpha$ and $\gamma$ phases.

\subsection{Positron annihilation measurements}

Figure 3 shows the value of $S$-parameter in temperature range $\mathrm{RT} \div 200^{\circ} \mathrm{C}$ during the isochronal ageing of quenched sample $A$. The ageing time at each temperature was $10 \mathrm{~min}$. While ageing at all temperatures, the value of $S$-parameter held constant. It suggests that positron annihilation in the vacancies frozen from high temperature $\beta$ phase only appears.

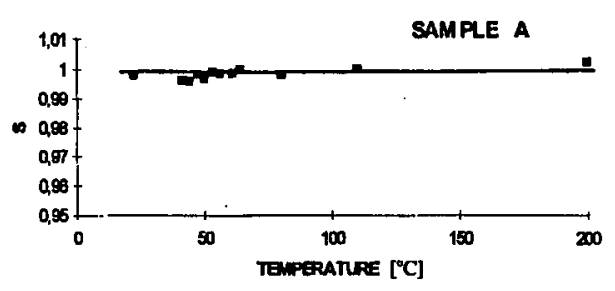

Fig. 3. The value of $S$-parameter during the isochronal ageing for $10 \mathrm{~min}$ at each temperature (sample A).

While isothermal ageing at $200^{\circ} \mathrm{C}$ the $S$-parameter increased with annealing time as shown in Fig. 4. Saturation of the $S$-parameter value occurs for the sample $\mathrm{A}$ aged for about $12 \mathrm{~h}$. This indicates that while ageing at $200^{\circ} \mathrm{C}$ the clusters of vacancies-Sn atoms can be produced [6] at the beginning of the formation of equilibrium $\alpha$ and $\gamma$ phases.

Figures 5 and 6 (sample A and B, respectively) show the mean positron lifetime as a function of isothermal $\left(200^{\circ} \mathrm{C}\right)$ annealing time. All experimental spectra (after subtraction of the positron source contribution) could only be described by one component fit. This indicates that in samples A and B all positrons are trapped 


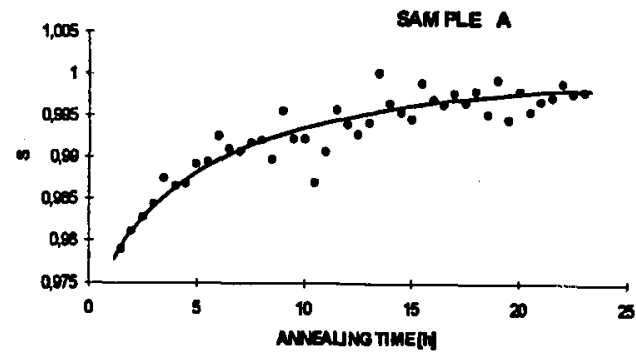

Fig. 4. The change in $S$-parameter during the isothermal ageing at $200^{\circ} \mathrm{C}$ (sample A).
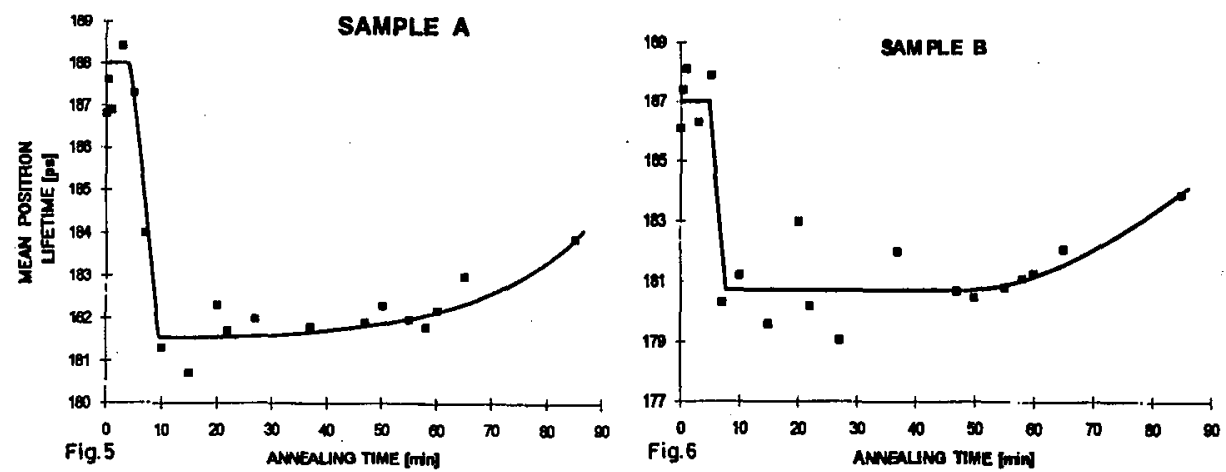

Fig. 5. Mean positron lifetime as a function of isothermal annealing time (sample A) Fig. 6. Mean positron lifetime as a function of isothermal annealing time (sample B).

into defects (vacancies of the parent phase). As for the Mössbauer measurements, two stages of ageing are also observed. The mean positron lifetime decreases while ageing at $200^{\circ} \mathrm{C}$ after about $5 \mathrm{~min}$. The value of $\tau$ shows the tendency of a slight increase after ageing for $60 \mathrm{~min}$, which indicates that the size of the clusters of vacancy-Sn atoms increases with annealing time. This change is in qualitative agreement with the results shown in Fig. 4.

\section{Conclusions}

1. Mössbauer effect and positron lifetime investigations indicate that in $\mathbf{A}$ and $B$ samples two different mechanisms of redistribution of Sn atoms in $\beta_{1}$ parent phase take place up to $5 \mathrm{~min}$ of annealing at $200^{\circ} \mathrm{C}$.

2. In the first stage of annealing up to $5 \mathrm{~min}$ the ordered distribution of $\mathrm{Sn}$ atoms in $\mathrm{DO}_{3}$ and $\mathrm{B} 2$ structure is observed. For the longer time of ageing, in the second stage, precipitations of phases $\alpha$ and $\gamma$ probably take place.

3. The positron annihilation Doppler broadening measurements show the vacancy-Sn clustering. Such a process makes the formation of equilibrium $\alpha$ and $\gamma$ phases easier for the longer annealing time. 


\section{References}

[1] Y. Ikai, K. Murakami, K. Mishina, J. Phys. Colloq. 43, C-4, 785 (1982).

[2] J. Morgiel, V.V. Martynov, J. Dutkiewicz, L.G. Khandros, in: Proc. XI Conf. on Appl. Cryst., Kozubnik 1984, Eds. Z. Bojarski, T. Bold, Institute of Ferrous Metallurgy, Gliwice 1984, p. 120.

[3] J.E. Frąckowiak, J. Morgiel, J. Dutkiewicz, Hyperfine Interact. 28, 1063 (1986).

[4] K. Płotkowski, T.J. Panek, J. Kansy, Nuovo Cimento D 8, 933 (1988).

[5] J.E. Frąckowiak, D. Ostrowski, in: Proc. XI Conf. on Appl. Cryst., Kozubnik 1984, Eds. Z. Bojarski, T. Bold, Institute of Ferrous Metallurgy, Gliwice 1984, p. 287.

[6] I. Tanaka, S. Nasu, F.E. Fujita, F. Ambe, S. Ambe, T. Okada, J. Phys. F, Met. Phys. 16, L151 (1986). 